scientific activity which involves a regular personal and intimate relationship between men of different nationalities that is affected by the action of these academies. The question, therefore, simply resolves itself into this. Is it possible that an international scientific meeting in which the belligerent countries sit side by side can, at the present moment, lead to any satisfactory results, or tend towards that reconciliation which the neutral countries very naturally and legitimately hope for? There can be but few who will answer that question in the affirmative, and it is doubtful whether those few would include anyone who has had experience of international meetings before the war. The questions discussed at these meetings frequently touch national interests or national ambitions, be it only a discussion whether units adopted in one country shall be universally accepted. It often requires tactful leadership and a conciliatory disposition on the part of everyone present to steer an international meeting to a successful issue.

The matter is, to a great extent, decided for us by Article 282 of the Treaty of Peace which Germany has ratified. According to that article, "treaties, conventions," and agreements of an economic and technical character" not included in a specified list cease to be operative. That this article was intended to cover conventions on scientific matters appears from the list of exceptions, in which the Metric Convention and the Agricultural Institute at Rome are included.

In view of the strong feelings of resentment which still exist between the belligerent nations, feelings shared by the great majority of their members, the alternatives possible to the allied academies were either to discontinue international unions or to proceed as they have done. The former course, not perhaps very harmful in some branches of science, would have been fatal in others, and in coming to a decision they have had to give the foremost consideration to the interests of science. It is intelligible that, both in the review of the past and in the outlook of the future, neutral opinion should differ from ours; but we may be confident that the academies of the nations to which the signatories of the appeal belong will, in considering the invitations which are to be sent to them, be guided in their response by the same interest for the future of scientific progress which lies at the heart of the allied academies.

\section{EVOLUTION OF OSTRICH PLUMES.}

PROF. J. E. DUERDEN has published (Bul1 letin No. 7, 19r8, Department of Agriculture, Union of South Africa, pp. 39, I2 figs.) a fourth report on his breeding experiments with ostriches at the Grootfontein School of Agriculture. His work is full of interest, both theoretically and practically. Birds brought from Nigeria have 33-39 first-row feathers on each wing, NO. 2608, VOL. IO4] with an arithmetical mean of 36.54 . If these imported birds represent a pure line, the likelihood is that the numerical variations are fluctuating somatic modifications, and that no amount of selection will increase the average number of plumes beyond that given. If the imported birds represent a mixed population of several pure lines, only appearing pure as a whole because of their small differences, it should be possible to obtain higher averages by always selecting as breeders the birds giving the highest number of plumes.

It turns out that Cape birds have the same number of plumes as the wild Nigerian birds, and it appears, therefore, that during the fifty years of ostrich farming in South Africa no advance whatever has been made on the number of plumes originally present on the wild bird. For farmers have always bred for quality; quantity has never been taken into account. As regards the number of plumes, ostrich-breeding has been carried on altogether indiscriminately, and no advance has been made.

Among the Cape birds in the Grootfontein flock there have been two cases of $4^{2}$ plumes to the first row. One of these met with a fatal accident; the other bred true. The 42-plumed bird might be regarded as a novel mutation, but there is a more plausible view. Recent studies on the ostrich afford strong evidence that the wings of its ancestors were much better covered with feathers than is the case to-day. There has been retrogression, and it is still continuing. The 42 -plumed wing is a survival of an ancestral condition. Very interesting facts are communicated in regard to the retrogressive or degenerative processes which are still going on in the ostrich's wing. The retrogression proceeds in one part of the wing quite independently of the other parts. Thus, apart from the plumes altogether, the third finger shows retrogression. It is almost buried in the flesh, and the claw which some books describe has never been found on the hundreds of birds coming under Prof. Duerden's observation. But a study of the plumes lends no countenance to the common view that degeneration takes place by slow, continuous stages. There may be the full presence of particular plumes in one individual, and their total absence in others; but there is not a gradual passage from full expression to the vanishingpoint. The degeneracy of an organ may stop at any stage according to the number of constituent factors which happen to be lost. We are apt to think of the degeneracy as a somatic affair, whereas it is germinal.

As to the possibilities of the 42-plumed survival, no chicks have yet been produced from the 42 plumed cock mated with a hen with the same number of plumes, for no hen has been forthcoming. But a score or so of chicks have been reared from the 42 -plumed cock crossed with different 36 -plumed hens, and these showed an interesting series of numbers from 37 to 43 . It seems probable, therefore, that if the 42 -plumed 
cock had been mated with a 42 -plumed hen there would have been a full 42-plumed progeny. If similar 42-plumed survivals occur, it should be possible for farmers to increase by as much as 25 per cent. the crop of feathers from the same number of birds, or, a more desirable outcome, to procure the same quantity of plumes from threequarters of their present number of birds. Prof. Duerden is to be congratulated on reaching conclusions at once of high theoretical interest and great practical utility.

\section{EDUCATION IN INDIA. ${ }^{1}$}

T'T HIS is the second quinquennial review compiled by Mr. Sharp, Educational Commissiontr with the Government of India. Shortage of paper and other conditions bred of a period of war have compelled him to curtail his report and, not without advantage, to diminish his statistics. What remains is full of interest and significance, especially, of course, to those who have some first-hand knowledge of Indian education. There is the inevitable, and in some respects useful, comparison with the educational statistics of various European countries and Japan. Of this it is necessary to repeat that the comparison is obviously unfair, even in the case of Japan. British India is a continent rather than a country, and is far more varied in culture and civilisation than Europe or Japan. It is the great towns, such as Calcutta or Bombay, that should be compared with European countries, since there alone are conditions sensibly similar to those of Western nations.

We should have welcomed, too, a fuller account of the attempts to impart instruction in the local languages. So long as British rule exists it will be as necessary for Indians to learn English as for educated Englishmen to learn French and German. But English as a medium of instruction is open to obvious objection. We continue to hear complaints of superficial thought, parrot learning of cram text-books, absence of originality, and so forth. Surely this is largely due to making lads, many of whom arè not gifted linguists, learn difficult subjects, such as science and mathematics, in a language in which they cannot think. Were it not that many Indians have attained to a surprising proficiency in English, the system would have been condemned long ago. In the chapter on Oriental teaching Mr. Sharp confines his remarks to education in the Indian classics, and has little or nothing to say of the attempts now being made to gain for the modern languages of India the same facilities that English universities are now supplying for European living speeches, their philology, phonology, and literature.

From the point of view of education in India, war and the economies it involved came at an

\footnotetext{
1 " Seventh Quinnuennial Review of the Prog:ess of F ducation in India." By H. Sharp. (Bureau of Education, India.) Price $5 s . t d$. net.
}

unfortunate moment, since it was necessary to suspend a great part of the reforms projected in Lord Hardinge's resolution of rgr3. Even in that circumstance, however, we may ultimately find comfort, since what India chiefly needs is not official encouragement and the vicarious liberality of Government so much as public appreciation of what good and solid education is and by what means it can be supplied to the people at large. One of the most important steps in this direction (less neglected than official reports seem to show) is to make the greater Indian languages fit vehicles for supplying instruction to immature minds. In many Indian provinces non-official committees and societies have carefully compiled vocabularies of scientific terms. Some of these seem pedantic and clumsy enough to those who study Indian languages merely with a view to the enjoyment of literature or the understanding of local life and character. But we must not forget that our own scientific nomenclature is chiefly borrowed from dead, inflected languages, and presents difficulties which, to an Indian mind, would not occur in the use of similar phrases borrowed from Sanskrit in the case of Hindu languages or from Arabic for Mohammedan learners of science.

On the whole, in spite of war and other lets and hindrances, some permanent, some, we hope, temporary, Mr. Sharp's admirably arranged and very valuable report tells us a tale of substantial progress. E pur si muove! Public expenditure on education has increased by one-half in the five years under review. There is a steady improvement in the number of boys and girls under instruction. Teachers are better paid, though it is probable that much of their increased salaries has been swallowed up by rising prices. The huge, too huge, examining universities are gradually being supplemented by smaller residential and teaching colleges. This change implies some recognition, on the part of Government and parents alike, of the fact that education comprises a moulding of character and will as well as the training of memory, intelligence, and interest.

It is perhaps a little surprising that Government reports on education do not deal with the significant results of school and university teaching as these appear in vernacular literature and journalism. Most of us in Europe have heard of Rabindranath Tagore and one or two other contemporary Indian authors. There are others, locally held in equal, or almost equal, esteem. A system of education which produces really fine literature, much of it entailing solid research and thought in history, in philosophy, and, to a growing extent, in science, is probably more full of hope and promise than can. well be shown in an official summary of the educational doings of some 200 millions of human beings of extraordinarily various degrees of social, religious, and scientific progress. This, of course, will be sufficiently apparent to any careful and disinterested reader of Mr. Sharp's admirable report. 